\title{
Diyetle Şeker Alımı: Tolere Edidebilir Üst Alım Miktarı
}

\author{
Dietary Sugar Intake: Tolerable Upper Intake Level
}

\author{
Prof. Dr. Ayla Gülden Pekcan ${ }^{1}$
}

\section{ÖZET}

Diyet farklı türde şekerler içerir. Bazıları üretim veya pişirme sırasında besinlere eklenmekte, bazıları da meyve, sebzeler, bal ve süt gibi besinlerde doğal olarak bulunmaktadır. Son yıllarda aşırı eklenmiş şeker tüketiminin diş çürükleri, fazla kilo ve obezite, metabolik sendrom ve kardiyovasküler hastalıklar gibi bulaşıcı olmayan kronik hastalıkların sağlık üzerine olası olumsuz etkileri araştırmaların önemli konusudur. Ayrıca enerji alımı eklenmiş şek erden gelen bireylerin diyet kalitelerinin düşük olduğu da rapor edilmiştir. Sağlık profesyonelleri uzun yıllardır eklenmiş şeker alımını sınırlandırmayı önermektedir. Dünya Sağlık Örgütü (WHO) artan bilime dayalı kanıtlar sonucunda 2015 yllında şeker alım rehberini güncellemiş ve eklenmiş şeker artı bal, meyve sularında bulunan doğal şekerler olarak tanımlanan "serbest şeker” üzerine odaklanmıştır. Yeni rehberlerde serbest şekerin diyette toplam enerjinin $<\% 10$ ’u olması, ek sağlık yararları için de toplam enerjinin $<\% 5$ ’e azaltılması önerilmiştir. Avrupa Gıda Güvenliği Otoritesi (EFSA) toplum görüşüne sunduğu ve 2021 yllı sonunda tüm kaynaklardan sağlanan diyet şekeri için bilime dayalı olarak Tolere Edilebilir Üst Alım Miktarı (UL) yayınlayacaktır. Ulusal otoritelerin diyetle eklenmiş/serbest şeker alımını azaltma için sağlıklı besin çevresi oluşturulmasını desteklemesi ve ulusal besin ve beslenme politikalarını oluşturması, uygulaması ve izlemesi gerekmektedir.

Anahtar kelimeler: Şeker, eklenmiş şeker, serbest şeker, diyet şekeri, UL

\begin{abstract}
Diet contains different kinds of sugars. Some are added to foods during production or cooking, others are naturally present in foods like fruit, vegetables, honey and milk. The potential negative effects of excessive added sugar intake on health outcomes have been an important topic of research in recent years. Studies have linked high added sugar consumption to dental caries, overweight and obesity, as well as various chronic diseases such as metabolic syndrome and cardiovascular diseases. Individuals who consume a high proportion of energy from added sugars were also reported to have poorer diet quality. Health care professionals have been recommending added sugar intake to be limited. Building upon the growing science-based evidence, the World. Health Organization (WHO) updated their guidelines on sugar intake in 2015, which focused on "free sugars," defined as added sugars plus natural sugars found in honey, syrups, and fruit juices. The new guidelines recommend that free sugar intake should contribute $<10 \%$ of the total energy intake of the diet, with a further reduction to $<5 \%$ of total energy for additional health benefits. European Food Safety Authority (EFSA) is publicly consulting on an opinion and will set a science-based Tolerable Upper Intake Level (UL) for dietary sugars from all sources by the end of 2021. National authorities should encourage building healthy food environment and develop, implement and monitor national food and nutrition policies for reducing added/free sugar intake in the diet is needed.
\end{abstract}

Keywords: Sugar, added sugar, free sugar, dietary sugar, UL

1. Hasan Kalyoncu Üniversitesi, Sağlık Bilimleri Fakültesi, Beslenme ve Diyetetik Bölümü, Gaziantep, Türkiye • E-posta: editor@beslenmevediyetdergisi.org (i) https://orcid.org/0000-0002-2037-3037 


\section{GİRIŞ}

Bulaşıcı olmayan kronik hastalıklar (kardiyovasküler hastalıklar, inme, bazı kanser türleri, kronik obstruktif pulmoner hastalıklar ve astım gibi kronik solunum hastalıkları, diyabet gibi) çevresel ve davranışsal, fizyolojik ve genetik etmenlerin etkisiyle ortaya çıkan ve günümüzde sıklıkla görülen bir halk sağlığı sorunu olduğu bilinmektedir. Bulaşıcı olmayan kronik hastalıklardan Dünyada her yll 41 milyon insanın öldüğü, bunun da tüm ölümlerin \%71'ine eşdeğer olduğu, 30-69 yaş arası ise 15 milyondan fazla insan öldüğü belirtilmektedir. Prematür ölümlerin \%85’i ve tüm bulaşıcı olmayan hastalıkların \%77'si ise düşük ve orta gelirli ülkelerde görülmektedir. Ölümlerde ilk sırada yılda 17.9 milyon kişi ile kardiyovasküler hastalıklar yer almakta, bunu kanserler (9.3 milyon), solunum hastalıkları (4.1 milyon) ve diyabet (1.5 milyon) izlemektedir. Bu dört tür hastalık tüm prematür bulaşıcı olmayan hastalıklardan ölümlerin \%80’ini oluşturmaktadır. Tütün kullanma, fiziksel aktivite azlığı, zararlı düzeyde alkol kullanımı ve sağlıksız diyet bulaşıcı olmayan hastalıklardan ölümleri arttırmaktadır. Saptama, tarama ve tedavi, palyatif bakım bulaşıcı olmayan hastalıkların yönetiminde önem taşımaktadır (1).

Sağllklı diyet her türlü kötü beslenmenin (malnutrisyon) bulaşıcı olmayan kronik hastalıklar önlenmesine yardımcıdır. Sağlıksız diyet ve fiziksel aktivite eksikliği (sedanter yaşam) sağllğın küresel riskleridir. Plansız şehirleşme, sağlıksız yaşam biçiminde küreselleşme ve toplumların yaşlanması bu hastalıkların görülme sıklığında artışın nedenlerindendir (1). Dünya Sağlık Örgütü (WHO) düzeltilebilir risk etmenleri olarak tütün kullanımını, aşırı tuz/sodyum alımını, alkol kullanımını ve fiziksel aktivite yetersizliğini metabolik risk etmenleri olarak da kan basıncında artışı (tüm ölümlerin \%19'unun nedeni), fazla kilo/obezite, hiperglisemi ve hiperlipidemiyi belirtmektedir (2).

Dünya Sağlık Örgütü’nün “Sağlıklı Diyet” (3) ve birçok uluslararası sağlık otoriteleri ve ülkemizde Sağlık Bakanlığı öncülüğünde alan uzmanları (diyetisyen, hekim, gıda mühendisi vd. beslenme ve gıda uzmanları) tarafından hazırlanmış olan “Türkiye Beslenme Rehberi (TÜBER) 2015” (4) sağlıklı beslenme ilkelerine dikkat çekmekte, toplumu ve sağlık profesyonellerini beslenmede farkındalığı arttırmaya, bilinçlendirmeye ve eğitimine katkıda bulunmaya, bilgi kirliliğini önlemeye ve aynı dili konuşmayı hedeflemektedir. TÜBER 2015, Türkiye Beslenme ve Sağlık Araştırması (TBSA) 2010 (5) veri tabanına göre hazırlanmıştır ve TBSA 2017 (6) veri tabanına göre güncellenmesi yapılmaktadır.

Dünya Sağlık Örgütü (3) sağlıklı beslenme uygulamalarının yaşamın ilk evrelerinde hatta gebelik öncesi, gebelik döneminde başlaması gerektiğini belirtmektedir. Anne sütü sağlıklı büyümeyi destekler, bilişsel gelişimi geliştirir, yaşamda uzun dönem etkileri ile yetişkinlik dönemi fazla kiloluluk ve obezite ile bulaşıcı olmayan kronik hastalık risklerini azaltir.

Bilindiği gibi sağlıklı beslenme ilkeleri ve genel yaklaşımları şöyle sıralanmaktadır. Enerji alımı enerji harcaması ile dengede olmalıdır. Sağlıksız vücut ağırlığı kazanımını önlemek için toplam yağ alımı enerji alımının \%30’unu geçmemelidir (7-9). Doymuş yağların alımı toplam enerjinin \%10'unun altında, trans yağların alımı toplam enerjinin \%1'inin altında olmall, yağ tüketimi doymuş yağlardan ve trans yağlardan doymamış yağlara (9) kaymalı ve endüstriyel üretimde oluşan trans yağların ortadan kaldırılması (eliminasyonu) amaçlanmalıdır (10-12).

Tuz alımının günde 5 gramın altında ( 2 g/gün sodyum eşdeğeri) tutulması yetişkinlerde hipertansiyonun önlenmesine yardımcı olmakta ve kalp hastalıkları ile inme riskini azaltmaktadır (13). WHO üye ülkeleri 2025 yllına kadar toplumun tuz tüketimini \%30 azaltmaya karar vermiş, aynı zamanda yetişkin ve adolesanlarda obezite ile diyabeti ve çocukluk çağı obezitesini 2025 yllına kadar yarıya indirmeyi kabul etmiştir (14,15). EFSA (16), 2019 yılında "Sodyum İçin Diyet Referans Değerleri” yayınlamıştır. Eldeki 
veriler "ortalama gereksinme (average requirementAR)" veya "toplum referans alım miktarı (population reference intake-PRI)" oluşturmak için yeterli bulunmamıştır. Avrupa toplumunda yetişkinler için $2.0 \mathrm{~g}$ sodyum/gün miktarı güvenilir ve yeterli alım miktarı (AI) olarak önerilmiştir. Bu miktarın kardiyovasküler hastalık riskini önlemede yeterli güvenirliği oluşturduğu bildirilmiştir. Aynı değer, gebe ve emziren kadınlara da uygundur. Çocuklar için değerler yetişkinlerin değeri temel alınarak, enerji gereksinmeleri ve büyüme faktörü dikkate alınarak uyarlanmıştır. Çocuklarda 1-3 yaş için 1.1 g/gün, 4-6 yaş için $1.3 \mathrm{~g} /$ gün, 7-10 yaş için $1.7 \mathrm{~g} / \mathrm{gün}, 11-17$ yaş için 2.0 g/gün önerilmiştir. Bebekler için (7-11 ay) AI: $0.2 \mathrm{~g} /$ gün olarak düşünülmüştür. Daha kapsamlı bilgi için EFSA Bilimsel Görüş Raporu’nun (16) incelenmesi önerilir.

Serbest şekerin de toplam enerjinin \%10'unun altına indirilmesi de sağlıklı beslenmenin parçasıdır $(7,17,18)$. Daha da ileri giderek ek sağlık yararları için toplam enerjinin \%5'inin altına düşürülmesi önerilmektedir (17). Serbest şekerin tüketilmesi diş çürükleri riskini artırmaktadır $(17,18)$. Son yıllarda aşırı eklenmiş şeker tüketiminin fazla kilo ve obezite (17), metabolik sendrom (19), ve kardiyovasküler hastalıklar $(20,21)$ gibi bulaşıcı olmayan kronik hastalıkların sağlık üzerine olası olumsuz etkileri araştırmaların önemli konusudur. Ayrıca enerji alımı eklenmiş şekerden gelen bireylerin diyet kalitelerinin düşük olduğu da rapor edilmiştir (22-28). Sağlık profesyonelleri uzun yıllardır eklenmiş şeker alımını sinırlandırmayı önermektedir. WHO artan bilime dayalı kanıtlar sonucunda 2015 yılında şeker alım rehberini güncellemiş ve eklenmiş şeker artı bal, meyve sularında bulunan doğal şekerler olarak tanımlanan "serbest şeker" üzerine odaklanmıştır. Yeni rehberlerde serbest şekerin diyette toplam enerjinin <\%10'u olması, ek sağlık yararları için de toplam enerjinin <\%5’e (25 g/gün: 6 tatlı kaşığı) azaltılması önerilmiştir (17). Rehberin Türkçesi "WHO. Rehber: Yetişkinler ve Çocuklarda Şeker Tüketimi” olarak Sağlık Bakanlığı sayfasında erişime açıktır (29). Besinlerden ve içeceklerden fazla serbest şeker alımı vücut ağırlığında sağlıksız artışa ve fazla kilo ile obeziteye neden olmaktadır. Son veriler serbest şeker alımının kan basıncı ve serum lipitlerini de etkilediğini ve serbest şeker alımının azaltılmasının kardiyovasküler hastalıkların risk etmenlerinde azalma sağladığını göstermektedir (30).

$\mathrm{Bu}$ derleme yazıda da sağlıklı beslenme uygulamalarında önemi nedeni ile şeker türleri, şeker tüketiminin/kullanımının azaltılması yaklaşımları ile Türkiye uygulamaları irdelenecektir.

\section{Şeker ve Şeker Türleri}

Diyetimizde farklı şeker türleri bulunmaktadır. Bazı şeker türleri besinlere eklenirken bazıları da meyve, sebze, bal ve sütte olduğu gibi besinlerde doğal olarak bulunmaktadır. Şekerler enerji kaynağıdır. Şeker tüketiminin diş çürüklerine neden olduğu bilinmektedir. Ayrıca, aşırı şeker tüketimi vücutta daha sonra kullanılmak üzere yağ olarak depo edilmekte ve zaman içerisinde sağlık sorunlarına neden olmaktadır. Diyetteki toplam şeker alt gruplarda sinıflanmakta ve irdelenmektedir. Toplam şekerler; a) meyve ve sebzeler ile sütte doğal olarak bulunan şekerler, b) serbest şekerler (doğal olarak bal, şurup, meyve ve sebze suları ve meyve konsantreleri ve eklenmiş şeker-rafine şeker dahil) olarak sınıflanmaktadır (Tablo 1) (18,31,32).

Türkiye Beslenme Rehberi (TÜBER)-2015 (4) göre, şeker; ticari olarak şeker pancarı, şeker kamışı veya nişastalı tahıllardan elde edilen bir bileşiktir. Günlük diyetle tüketilen toplam şeker miktarını besinlerin doğal olarak yapısında bulunan ve besinlerin işlenmesi sırasında ilave edilen (eklenen şeker) şekerlerin oluşturduğu belirtilmektedir. Toplam enerjinin \%10’unu geçmemesi önerilmektedir.

TÜBER’e göre; 1) Besinlerde doğal bulunan şekerler; örneğin sütte bulunan laktoz, meyvelerde bulunan früktoz vb. gibidir. 2) İlave (eklenen) şeker kaynakları: Şekerli içecekler (kolalı, meyveli, gazlı içecekler, limonata), şekerler, şekerlemeler (akide şekeri, lokum vb.), kekler, pastalar, turtalar, kurabiyeler, meyve nektarı, hamur işi tatlılar, helvalar, sütlü tatlılar, 
Tablo 1. Diyet şekeri sınıflaması ve alt grupları $(18,31,32)$

TOPLAM ŞEKER

DOĞAL ŞEKERLER + SERBEST (EKLENMIŞ DAHIL) ŞEKERLER

\begin{tabular}{ll}
\hline DOĞAL ŞEKERLER & Meyveler \\
& Sebzeler \\
Süt
\end{tabular}

EKLENMIŞ ŞEKER

(Serbest şeker + eklenmiş şeker)

SERBEST ŞEKERLER

Bal

Şurup

Meyve ve sebze suları

Meyve ve sebze suyu konsantreleri

EKLENMIŞ ŞEKER

Rafine şeker (çay şekeri) (hazırlama, işleme sırasında eklenen şeker)

dondurma, tatlı yoğurt, reçel, marmelat, şekerli hazır sütler, çikolata ve şeker ilave edilmiş tahıl ürünleridir. İlave (ek) şekerler, beyaz şeker, esmer şeker, nişasta bazlı şeker gibi şeker içeren ürünleri kapsamaktadır. Şeker; besinlere ve içeceklere tat vermek, dayanıklılığını/raf ömrünü artırmak, yapısını ve kıvamını sağlamak amacıyla eklenmektedir diye ifade edilmiştir (4).

\section{Beslenmede Şekerin Azaltılmasında Uluslararası Kuruluşların Yaklaşımı}

\section{Dünya Sağlık Örgütü (WHO)}

Dünya Sağlık Örgütü şeker tüketiminin azaltılmasını önermekte, günlük enerjinin \%10'dan azının şekerden gelmesini (mümkünse ek sağlık yararları için \%5'in altında olması) önermektedir. Yiyeceklerin doğal yapısında bulunan şeker dışında tüketici tarafindan tüketilen serbest şekerlerin günlük tüketim miktarı, ihtiyaç duyulan günlük enerji miktarının \%10’unu geçmemelidir $(17,29)$.

Şeker tüketiminin azaltılması için öneriler şöyle sıralanmaktadır. 1) Yüksek miktarda şeker içeren (şekerli atıştırmalıklar, şekerler, şeker içeren gazlı ve gazsız içecekler, meyve veya sebze suları ve içecekler, sıvı ve toz konsantreler, aromalı sular, enerji ve sporcu içecekleri, içime hazır çay ve kahveler, aromalı süt içecekleri gibi) besinlerin ve içeceklerin tüketiminin sınırlandırılması, 2) Şekerli atıştırmalıkların yerine taze meyve ve çiğ sebzelerin tüketilmesi (3).

\section{Avrupa Gıda Güvenliği Otoritesi (EFSA)}

Bilindiği gibi EFSA beslenme alanında halk sağlığı otoritelerine "bilimsel kanita dayall" öneriler sunmaktadır. EFSA politika önerileri yapmamakta veya halk sağlığı rehberleri oluşturmamaktadır. Avrupa'da 5 Nordik Avrupa ülkesi (Danimarka, Finlandiya, İzlanda, Norveç ve İsveç) EFSA'ya tüm kaynaklardan sağlanan diyet şekeri için kronik metabolik hastalıklar (örneğin, obezite, tip 2 diyabet, kardiyovasküler hastalıklar, gut), gebelik ilintili etkileri ve diş çürükleri konusunda elde bulunan veriler doğrultusunda bilime dayalı "Tolere Edilebilir Üst Alım Miktarı (UL-Üst Limit)” belirlenmesi için başvuru yapmıştır. Bu doğrultuda EFSA'ya tüketicilerin diyetlerinde ne miktarda şeker olmalıdır sorusu sorulmamıştır. Bu konu ulusal halk sağlığı otoritelerinin ve WHO’nun görevi olduğu da özellikle belirtilmiştir $(18,31,32)$.

EFSA’nın bilim uzmanları bu doğrultuda literatürün sistematik derlemesini yürütmüş ve 2018 yılında 25 000 ve 2020 yılında da ek olarak 7500 bilimsel yayın taradığı bilinmektedir. Kronik metabolik hastalıklar, gebelik ilintili etkileri ve diş çürükleri konusunda 
şeker tüketimi bağlantılı 120 yayın elde edilmiştir. Kullanılan yöntem için oluşturulan EFSA protokolü çalışma başlamadan önce 2018 yılında tanımlanmıştır. Ayrica uzmanlar tarafından toplam 135000 kişiyi içeren 25 Avrupa ülkesinin standart besin tüketim araştırması verilerinden farklı besin kategorilerinden sağlanan şeker alımları belirlenmiştir $(18,31,32)$.

EFSA tarafından tüketici için belirlenen riskler: Çok fazla sayıda bilimsel yayın taranmasına rağmen elde edilen verilerden diyetle şeker alımı için "Tolere Edilebilir Üst Alım Miktarı (UL) veya Güvenilir Alım Miktarı"nın belirlenemediği sonucuna varıldığı EFSA raporunda yer almıştır. Ancak uzmanlar tarafından risklerin rakamsal riskleri tanımlanamamasına karşın şeker tüketimi ile sağlık sorunları arasındaki "farklı kesinlik (certainty) dereceleri” onaylanmıştır. Diş çürükleri ile ilgili risk ilişki iyi tanımlanmış ve beslenme açısından yeterli diyet için olabildiğince diyetle toplam şeker alımı azaltılmalıdır denilmiştir. Kronik metabolik hastalıklar ile diş çürüklerinde ilave ve serbest şeker alımı da olabildiği kadar az olmalıdır sonucuna varılmıştır (Tablo 2).

EFSA “taslak bilimsel rapor” 22 Temmuz-30 Eylül 2021 tarihleri arasında genel görüşe açılmıştır. EFSA 21 Eylül 2021 tarihinde taslak bilimsel görüş raporu için çevirimiçi genel toplantı yapmayı planlamıştır. Çalışma 2021 yılı sonunda tamamlandıktan sonra EFSA bilimsel görüşü Avrupa ülkelerinin toplum hedeflerini ve/veya ülkelerin bireyleri için öneriler oluşturulmasına yardımcı olacaktır $(18,31,32)$.

\section{Türkiye'de Şeker Tüketimi: TBSA 2010 ve 2017} Verileri

TBSA 2010 (5) ve TBSA 2017 (6) verilerine göre 15 ve üzeri ile 15-18 yaş, 19-64 ve 65 yaş üzeri bireylerde günlük şeker alım miktarları (g) irdelendiğinde şu sonuçlar elde edilmiştir. Sofra şekerinin 15 yaş üzeri kişilerde günlük tüketimi yaklaşık $20 \mathrm{~g}$ ve toplam şeker 31 gramdır. Yaş gruplarına göre bakıldığında 1964 yaş grubu erkeklerde şeker tüketiminin daha fazla (Erkek: 24.4 ve Kadın 17.6 g/gün) olduğu belirlenmiştir TBSA 2010 (5) ve TBSA 2017 (6) verilerine göre 19 yaş ve üzeri bireylerde günlük ortalama şeker ve şekerli besinlerin tüketim miktarı erkeklerde kişi başı TBSA 2010'da günlük 36.6 gram iken TBSA 2017'de 34.9 gramdır. Kadınlarda ise TBSA 2010'da şeker ve şekerli besinler tüketimi 28.7 gram iken TBSA 2017'de 26.4 gramdır. Toplamda TBSA 2010'da tüketim 33.0 g/gün iken TBSA 2017'de 30.6 g/gündür. Türkiye genelinde sofra şekerini hiç tüketmeyenlerin sıklığı \%27.7, her gün tüketenlerin sıklığı \%60.9, haftada bir kez tüketenlerin sıklığı ise \%2.3’dür.

Türkiye Beslenme ve Sağlık Araştırması (TBSA) 2010 çalışmasında şeker tüketiminin bölgelere, cinsiyete ve yaş gruplarına göre ileri analizi yapılmış ve 97.5.

Tablo 2. Şekerler ve sağlık sorunları ilişkisi (kesinlik derecesi \%) $(18,31,32)$

\begin{tabular}{lcccc}
\hline & $\begin{array}{c}\text { Ek (İlave) ve } \\
\text { serbest şeker }\end{array}$ & Fruktoz & $\begin{array}{c}\text { Şekerle tatlandırılmış } \\
\text { içecekler }\end{array}$ & \%100 meyve suyu \\
\hline Matabolik hastalıklar & & & & \\
Obezite & $50-75$ & SY & $75-100$ & $<15$ \\
Karaciğer hastalığı (NAFLD) & $15-50$ & SY & $15-50$ & SY \\
Tip 2 diyabet & $15-50$ & SY & $75-100$ & $50-75$ \\
Kötü huylu kolesterol yüksekliği (Dislipidemi) & $50-75$ & SY & $15-50$ & SY \\
Hipertansiyon & $<\% 15$ & SY & $75-100$ & SY \\
Kardiyovasküler hastalık & SY & $15-50$ & $75-100$ & SY \\
Gut & SY & $50-75$ & $50-75$ & $50-75$ \\
Gebelik-ilintili & SY & SY & $<15$ & SY \\
Diyabet & SY & SY & $15-50$ & SY \\
Küçük bebek & SY & SY & $15-50$ & SY \\
\hline
\end{tabular}

<\%15: çok düşük; \%15-50: düşük; \%50-75: orta; \%75-100: yüksek; SY: sonuç yok 
persentil değerindeki tüketim miktarları (g/gün) değerlendirildiğinde alım miktarının en yüksek 1864 yaş grubunda olduğu (123 g/gün), erkeklerde kadınlara göre daha fazla olduğu (E: 123 g/gün, K: 108 g/gün) belirlenmiştir. Bölgelere göre ise 97.5. persentil değerinde tüketim miktarının en yüksek olduğu bölgenin Doğu Marmara Bölgesi (129 g/gün), tüketim miktarının en düşük olduğu bölgenin ise Orta Doğu Anadolu Bölgesi olduğu (99 g/gün) görülmüştür. Tüm yaş gruplarında şeker tüketimi için önerilen enerjinin \%5-10'u kadar şeker tüketenlerin sıklığı sadece \%3040 aralığında bulunmuştur. Enerjinin \%10-20'si kadar şeker tüketenlerin sıklığı \%30-40 aralığında yer almaktadır. Şekeri enerjinin \%20'sinin üzerinde tüketenlerin sıklığı toplumda \%10'un altındadır (4).

\section{Türkiye'de Şeker Tüketiminin/ Kullanımının Azaltılması Programı}

Obezite ve diğer bulaşıcı olmayan hastalıkların gelişmesinde beslenme önemli rol oynamaktadır. Bilimsel çalışmalarda, şeker ve şeker ilave edilmiş besinlerin fazla miktarda tüketiminin başta obezite olmak üzere, kardiyovasküler hastalıklar, diş çürükleri, bazı kanser türleri, tip 2 diyabet ve bazı metabolik sorunlara neden olabileceği için tüketiminin azaltılması gerektiği belirtilmektedir.

Türkiye Beslenme ve Sağlık Araştırması (2017) sonuçlarına göre ülkemizde 15 ve üzeri yaş grubu bireylerde obezite sıklığ $\% 31.5$, inaktif nüfus $\% 42.4$, diyabet ise \%12.1 olarak belirlenmiş olup tüm hastalıklar içerisinde bulaşıcı olmayan hastalık yükü ilk siraları tutmaktadır (6).

Bu bağlamda T.C. Sağlık Bakanlığı sağlıklı beslenmenin teşvik edilmesi ve bulaşıcı olmayan hastalıkların önlenmesi amacıyla güncellenerek yürütülen "Sağlıklı Beslenme ve Hareketli Hayat Programı ve Eylem Planı" kapsamında toplumda sağlıklı beslenme alışkanlıklarının teşvik edilmesi çalışmaları içerisinde şeker tüketiminin azaltılması için gerekli önlemlerin alınması yer almaktadır (33-35).
Sağlık Bakanlığı ile Türkiye Gıda ve İçecek Sanayii Dernekleri Federasyonu (TGDF) iş birliğinde hazırlanan "Şeker Azaltma Rehberi" (36) ile çikolata, şeker, gofret, enerji barı, tatlı sos, kahvaltılık gevrek ve alkolsüz içecek gibi ürünlerde şeker kullanımının 2025’e kadar tedrici olarak \%10 azaltılması hedeflenmiştir. Hazırlanan raporda enerji ihtiyacı ortalama $2000 \mathrm{kkal}$ olan bir kişi için toplam enerjinin \%10’u 200 kkal yapmakta olup yaklaşık 50 g (20 adet küp) şekere eş değer olduğu belirtilmiştir. Bilindiği gibi 1 tatlı kaşığı ve 2 adet kesme şeker 5 gram şeker (20 kkal) içermektedir. Bir tatlı kaşığı reçel (12 g) ve bal (8 g) tüketildiğinde sirasıyla $6.8 \mathrm{~g}$ (27 kkal) ve 5.8 g (23 kkal) şeker içermektedir. Kolalı içecek 330 mL (1 kutu) $37 \mathrm{~g}$, meyve aromalı gazlı bir içecek (225 mL) ise 29.4 g, 250 mL (bir kutu) enerji içeceği ise 28.2 g, sütlü çikolata kaplı kakao kremalı gofret (35 g) 9.28 g, 2 top dondurma (100 g) 22 g şeker içermektedir (36).

Sağlık Bakanlığı Halk Sağlığı Genel Müdürlüğü ile TGDF'nin “Sağlıklı Beslenme ve Hareketli Hayat Programı ve Eylem Planı" kapsamında, 2020'de imzaladığı "Şeker Azaltma İş Birliği Protokolü" kapsamında hazırlanan "Türkiye Şeker Tüketimini/ Kullanımını Azaltma Rehberi” doğrultusunda doküman, 14 Temmuz 2021 tarihinde tarafların katıldığı çevrim içi düzenlenen toplantıyla kamuoyuna tanıtılmıştır.

Ambalajlı ürünler ile lokanta ve kafe menülerinde şeker oranlarının azaltılması amaçlanmıştır. Dünya Sağlık Örgütünün şeker tüketiminin azaltılmasını, günlük enerjinin \%10'dan azının şekerden gelmesini (50 g, 20 adet kesme şeker), hatta mümkünse bu oranın \%5'in altında olmasını önermesi dikkate alınmıştır. Bu doğrultuda toplumda şeker tüketimini azaltmak için yapılabilecek çalışmalar konusunda bilgilendirme yapmak ve yönlendirmek amacıyla bu rehber hazırlanmıştır. Hedef, ürünlerdeki şeker oranını 4 yılda \%10 azaltmaktır. Gıda üreticisi firmaların şeker tüketiminin azaltılması için gönüllü taahhütte bulunduğu ve iş birliği içerisinde hazırlanan "Türkiye Şeker Tüketimini/Kullanımını Azaltma Rehberi” 
kapsamında 2025’e kadar tedrici olarak \%10 şekeri azaltılacak besinler şöyle belirlenmiştir (36).

- Çikolata ve şekerler, gofretler, enerji barları, tatlı soslar ve tatlllar (Kakao ve Çikolata Ürünleri Tebliği kapsamında tanımlanan ürünler, şekersiz tatllar ve sakız hariç tüm şekerleme ürünleri, çikolatall ve kakaolu tüm sürülebilir ürün çeşitleri, diğer tatl sandviç sosları, findık-fistık-badem vb. ezmeleri).

- Hafif firıncılık ürünleri (tahıll barlar dahil olmak üzere tüm tatlı bisküvi çeşitleri, glutensiz bisküviler, kruvasan, kurabiye, pandispanya, waffle ürünleri, meyveli paylar ve tatlı çörekler, kek karışımları, pastanecilik ürünleri).

- Alkolsüz içecekler.

- Dondurma, dondurulmuş yoğurt, buzlu şekerlemeler ve sorbelerin içerisinde olduğu yenilebilir buzlar.

- Kahvaltılık gevrekler (tüketime hazır tüm tahıll veya yulafli gevrekler, yulaf ezmesi, granola, müsli barlar, çikolatalı kahvaltılı gevrekler.)

- Çeşnili fermente süt ürünleridir.

\section{SONUÇ}

Ulusal otoritelerin diyetle eklenmiş/serbest şeker alımını azaltma için sağlıklı besin çevresi oluşturulmasını desteklemesi ve ulusal besin ve beslenme politikalarını oluşturması, uygulaması ve izlemesi gerekmektedir. Bu doğrultuda "Sağlıklı Beslenme ve Hareketli Hayat Programı ve Eylem Planı” kapsamında, Sağlık Bakanlığı'nın 2020'de imzaladığı "Şeker Azaltma İş Birliği Protokolü" kapsamında hazırlanan "Türkiye Şeker Tüketimini/ Kullanımını Azaltma Rehberi” doğrultusunda yaklaşımlar büyük önem taşımaktadır. Halkın beslenmede bilinçlendirilmesi ve eğitimi kapsamında diyetisyenler diğer kurum ve kuruluşlarla birlikte büyük görev ve sorumluluklar taşımaktadır.

\section{KAYNAKLAR}

1. WHO. Key facts. Noncommunicable Diseases. 2021. Available at: https://www.who.int/news-room/factsheets/detail/noncommunicable-diseases Accessed July 22, 2021.

2. GBD 2015 Risk Factors Collaborators. Global, regional, and national comparative risk assessment of 79 behavioural, environmental and occupational, and metabolic risks or clusters ofrisks, 1990-2015: a systematic analysis for the Global Burden of Disease Study 2015. Lancet. 2016;388(10053):1659-724.

3. WHO. Healthy diet. Key facts. April 29, 2020. Available at: https://www.who.int/news-room/fact-sheets/detail/ healthy-diet Accessed July 22, 2021.

4. T.C. Sağlık Bakanlığı, Türkiye Beslenme Rehberi (TÜBER) 2015. T.C. Sağlık Bakanlığı Yayın No: 1031, Ankara 2016.

5. Türkiye Beslenme ve Sağlık Araştırması (TBSA). 2010. Available from: https://hsgm.saglik.gov.tr/depo/birimler/ saglikli-beslenme-hareketli-hayat-db/Yayinlar/kitaplar/ diger-kitaplar/TBSA-Beslenme-Yayini.pdf. Accessed July 22, 2021.

6. Türkiye Beslenme ve Sağlık Araştırması (TBSA). 2017. Available from: https://hsgm.saglik.gov.tr/depo/birimler/ saglikli-beslenme-hareketli-hayat-db/Yayinlar/kitaplar/ TBSA_RAPOR_KITAP_20.08.pdf. Accessed July 22, 2021.

7. WHO/FAO. Diet, nutrition and the prevention of chronic diseases: report of a Joint WHO/FAO Expert Consultation. WHO Technical Report Series, No. 916. Geneva: World Health Organization; 2003.

8. Hooper L, Abdelhamid A, Bunn D, Brown T, Summerbell CD, Skeaff CM. Effects of total fat intake on body weight. Cochrane Database Syst Rev. 2015;(8):CD011834.

9. FAO. Fats and fatty acids in human nutrition: report of an expert consultation. FAO Food and Nutrition Paper 91. Rome: Food and Agriculture Organization of the United Nations; 2010.

10. Nishida C, Uauy R. WHO scientific update on health consequences of trans fatty acids: introduction. Eur J Clin Nutr. 2009;63 (Suppl 2):1-4.

11. WHO. Guideline: Saturated fatty acid and trans-fatty acid intake for adults and children. Geneva: World Health Organization; 2018.

12. WHO. An action package to eliminate industriallyproduced trans-fatty acids. WHO/NMH/NHD/18.4. Geneva: World Health Organization; 2018.

13. WHO. Guideline: Sodium intake for adults and children. Geneva: World Health Organization; 2012. 
14. WHO. Comprehensive implementation plan on maternal, infant and young child nutrition. Geneva: World Health Organization; 2014.

15. WHO. Global action plan for the prevention and control of NCDs 2013-2020. Geneva: World Health Organization; 2013.

16. EFSA NDA Panel (EFSA Panel on Nutrition, Novel Foods and Food Allergens), Turck D, Castenmiller J, de Henauw S, Hirsch-Ernst K-I, Kearney J, et al. 2019. Scientific Opinion on the dietary reference values for sodium. EFSA Journal 2019;17(9):5778.

17. WHO. Guideline: Sugars intake for adults and children. Geneva: World Health Organization; 2015.

18. EFSA. EFSA explains draft scientific opinion on a tolerable upper intake level for dietary sugars. July 22, 2021. Available at: https://www.efsa.europa.eu/en/ corporate-pubs/efsa-explains-draft-scientific-opiniontolerable-upper-intake-level-dietary-sugars Accessed July 22, 2021.

19. Cottrell RC. Sugar: an excess of anything can harm. Nature. 2012;483(7388):158.

20. Johnson RK, Appel LJ, Brands M, Howard BV, Lefevre M, Lustig RH, et al. Dietary sugars intake and cardiovascular health: a scientific statement from the American Heart Association. Circulation. 2009;120(11):1011-20.

21. Watts G. Sugar and the heart: old ideas revisited. BMJ. 2013;346:e7800.

22. Louie JC, Tapsell LC. Association between intake of total vs added sugar on diet quality: a systematic review. Nutr Rev. 2015;73(12):837-57.

23. Moshtaghian H, Louie JC, Charlton KE, Probst YC, Gopinath B, Mitchell P, et al. Added sugar intake that exceeds current recommendations is associated with nutrient dilution in older Australians. Nutrition. 2016;32(9):937-42.

24. Livingstone MB, Rennie KL. Added sugars and micronutrient dilution. Obes Rev. 2009;10(Suppl 1):3440.

25. Louie JC, Tapsell LC. Intake of total and added sugars and nutrient dilution in Australian children and adolescents. Br J Nutr. 2015;114(11):1875-86.

26. Fulgoni 3rd VL, Gaine PC, Scott MO, Ricciuto L, DiFrancesco L. Association of added sugars intake with micronutrient adequacy in US children and adolescents: NHANES 2009-2014. Curr Dev Nutr. 2019;3(12):nzz126.

27. Mok A, Ahmad R, Rangan A, Louie JCY. Intake of free sugars and micronutrient dilution in Australian adults. Am J Clin Nutr. 2018;107(1):94-104.

28. Wong THT, Mok A, Ahmad R, Rangan A, Louie JCY. Intake of free sugar and micronutrient dilution in Australian children and adolescents. Eur J Nutr. 2019;58(6):248595.

29. Dünya Sağlık Örgütü. Rehber: Yetişkinler ve çocuklarda şeker tüketimi. 2015. Erişim: https://hsgm.saglik.gov. tr/depo/birimler/saglikli-beslenme-hareketli-hayat-db/ Yayinlar/rehberler/Yetiskinler-ve-Cocuklarda-SekerTuketimi-Rehberi.pdf Erişim Tarihi: 22 Temmuz 2021.

30. Te Morenga LA, Howatson A, Jones RM, Mann J. Dietary sugars and cardiometabolic risk:systematic review and meta-analyses of randomized controlled trials of the effects on bloodpressure and lipids. AJCN. 2014;100(1):65-79.

31. EFSA. Draft conclusion on sugar consumption and health. Infographic information. July, 2021.

32. EFSA. Scientific opinion on the Tolerable Upper Intake Level for dietary sugars. EFSA Journal. Available at: https://open.efsa.europa.eu/consultation/ a0c1v00000HdaQMAAZ Accessed: July 22, 2021.

33. T.C. Sağlık Bakanlığı Türkiye Halk Sağlığı Kurumu. Türkiye Sağllklı Beslenme ve Hareketli Hayat Programı (2014-2017). Ankara, 2013. Erişim: https:// www.beslenmehareket.saglik.gov.tr Erişim Tarihi: 22 Temmuz 2021.

34. T.C. Sağlık Bakanlığı Türkiye Sağlıklı Beslenme ve Hareketli Hayat Programı Yetişkin ve Çocukluk Çağı Obezitesinin Önlenmesi ve Fiziksel Aktivite Eylem Planı 2019-2023. Ankara, 2019. Erişim: https://hsgm.saglik.gov. tr/depo/birimler/saglikli-beslenme-hareketli-hayat-db/ programlar/Eylem_Plani_2019_01_12_2020 .pdf Erişim Tarihi: 22 Temmuz 2021.

35. TC. Sağlık Bakanlığı. Türkiye Sağlıklı Beslenme ve Hareketli Hayat Programı. Çocukluk Çă̆ı Obezitesinin Önlenmesi ile İlgili Eylem Planı 2019-2023 Sağlık Bakanlığı, Halk Sağlığı Genel Müdürlüğü, Sağlık Bakanlığı Yayın No: 773, Ankara 2019. Erişim: https:// hsgm.saglik.gov.tr/depo/birimler/saglikli-beslenmehareketli-hayat-db/TSBHHP_2019-2023_Cocukluk_Cagi/ Cocuk_Eylem_Plani_2019-_16.12.2019.pdf Erişim Tarihi: 22 Temmuz 2021.

36. T.C. Sağlık Bakanlığı. Türkiye Şeker Tüketimini/ Kullanımını Azaltma Rehberi. T.C. Sağllk Bakanlığı Yayın No: 1201. Halk Sağlığı Genel Müdürlüğü Matbaası. Ankara, 2021. 